\title{
Falsas respostas à "crise ambiental"
}

\author{
Maria Elisabeth Duarte Silvestre
}

\section{Resumo}

Arguo que o mais importante efeito da "crise ambiental" tem sido a ampliação do mercado via valoração monetária da natureza. Destaco a mobilização das agências multilaterais, do Estado e do pensamento acadêmico em defesa de um "desenvolvimento sustentável" baseado no aprofundamento das relações mercantis.

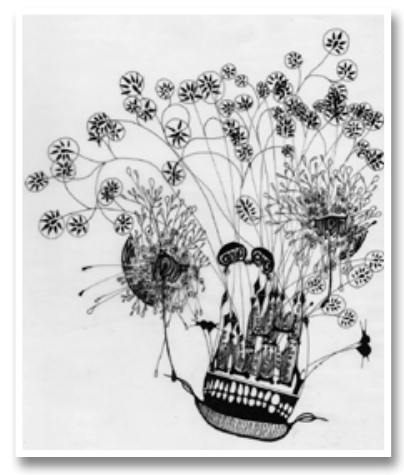

Palavras-chave: Crise Ambiental; Política Ambiental;

Desenvolvimento Sustentável.

\section{$\overline{\text { Maria Elisabeth Duarte }}$ SILVESTRE}

Doutora em Geografia pela Universidade Federal Fluminense/(UFF) e professora do Departamento de Economia da Universidade Federal do Piauí/(UFPI).

\section{False answers to the "environmental crisis"}

\begin{abstract}
I argue that the most important effect of "environmental crisis" has been the amplification of the market through the monetary valorization of nature. I highlight the mobilization of multilateral agencies, the State and the academic thought in the defense of a "sustainable development" based on the deepening of market relations.
\end{abstract}

Keywords: Environmental Crisis; Environmental Policy; Sustainable Development. 


\section{INTRODUÇÃO}

Neste artigo, reflito sobre a ampliação do mundo das mercadorias mediante valoração monetária da natureza e suas repercussões sobre as relações internacionais. Esta tendência se apresenta, à primeira vista, como decorrente da "crise climática", "crise ambiental", "questão ambiental", "problema ambiental", expressões pouco precisas (aqui, empregadas como sinônimo) que há mais de duas décadas rendem farta literatura, justificam investimentos em novas tecnologias, inspiram a criação de entidades da sociedade civil, induzem a emergência de novas instâncias de poder, aparatos jurídicos específicos e fóruns de diferentes alcances.

Hoje, a "crise ambiental" destaca-se na pauta política, mas, a rigor, diz respeito às possibilidades de preservação das perspectivas socioeconômicas mundiais nos moldes em que se apresentam. Em outras palavras, põe em xeque os fundamentos daquilo usualmente designado como "desenvolvimento econômico".

Insiro-me entre os que acreditam que a natureza apropriada e transformada em recurso deixa de ser natural e torna-se social. A Terra é finita e sujeita a transformações decorrentes de fenômenos físicos e químicos que ocorrem a revelia da ação humana. Mas, na configuração da chamada crise ambiental não estão em causa limites fisioquímicos absolutos nem relações de sociedades genéricas com a natureza. Trata-se dos limites de uma forma particular de relação social: aquela que tem como móvel a acumulação da riqueza abstrata.

Destaco a mobilização das agências multilaterais no processo de incorporação do "ambientalismo" pelo Estado e da institucionalização da ideia de "desenvolvimento sustentável" a partir do aprofundamento das relações mercantis. Concluo que a proteção do ambiente, que mobiliza crescente número de pessoas, não pode ser dissociada da luta por novas relações sociais e novas institucionalidades políticas. 


\section{A INSTITUCIONALIZAÇÃO DO AMBIENTALISMO}

Depois da Segunda Guerra, pela primeira vez, além da correlação de forças entre potências, esteve em jogo a preservação de sistemas socioeconômicos, culturais e ideológicos distintos. Diante da bipolaridade e da expansão da influência socialista, os Estados capitalistas se mostrariam coesos e, contrariando previsões, os anos que se seguiram foram de acelerado crescimento econômico. Por três décadas, sob a liderança dos Estados Unidos ou da União Soviética, capitalistas e socialistas pareciam ter descoberto o caminho para driblar crises econômicas (HOBSBAWM, 1995).

A conflagração fortalecera os Estados Unidos. Enquanto desequilíbrios nas contas externas, desemprego, racionamento de alimentos e de energia assolavam a Europa, o PNB norte-americano aumentava espetacularmente. Este país tornou-se o maior credor mundial, respondeu pela metade da produção de bens e serviços no Globo e, apenas dois anos depois da Guerra, suas reservas em ouro correspondiam a $70,0 \%$ das reservas globais (MELLO, 1999).

Bretton Woods (1944) resultara no reconhecimento do dólar como moeda de referência internacional, na constituição do Banco Internacional de Reconstrução e Desenvolvimento (BIRD) e do Fundo Monetário Internacional (FMI). No lugar da Liga das Nações, mas sempre acenando com a ideia de progresso e paz, instituiu-se a ONU. Em 1947, um instrumento de controle do comércio internacional foi formalizado (GATT). Neste âmbito, os Estados Unidos firmaram a solvência dos seus devedores e ampliaram as possibilidades de realização dos seus capitais. Na Europa, com políticas compensatórias e subsídios, o desemprego e o racionamento ensejaram elevados níveis de produção, produtividade e aumentos reais de salários. A recuperação do Japão foi estonteante: em 1951, seu PNB alcançava os níveis de 1934-36 e na década de 1960 sua taxa de crescimento chegou a $11 \%$ a.a. (JAPÃO, 2013).

Em 1950 e 1970, o comércio de manufaturas decuplicou. A agropecuária elevou a produção de alimentos e matérias-primas. Entre 1950-52 e 1980-82, o volume de grãos produzidos mais do que dobrou na América do Norte, na Europa Ocidental e no Leste da Ásia e a indústria da pesca triplicou. Apesar da acentuada 
urbanização e do crescimento populacional, o malthusianismo foi enterrado, enquanto a fome seguia como realidade para milhões, porém debitada aos desígnios divinos ou azares da natureza. $\mathrm{O}$ desenvolvimento fundado na industrialização e conduzido por capitais privados ou pelo Estado foi a tônica, atingindo inclusive a América Latina e a África.

Com o avanço da ciência e das comunicações impulsionou-se o otimismo quanto ao desenvolvimento como destino da humanidade, entretanto ensejou-se também o questionamento da sua continuidade ad infinitum a partir dos seus fundamentos físicos e biológicos: produzir é transformar matéria natural em utilidades, mas a produção não pode crescer ilimitadamente, pois a regeneração e/ou a adaptação dos ecossistemas obedecem a ciclos que requerem tempos e condições específicas para se completarem.

Essas evidências fundamentaram o ambientalismo nascido na segunda metade do século XX. Inicialmente restritas a cientistas vinculados às Ciências da Natureza, as preocupações com o meio ambiente foram expressas já em 1949, quando a ONU promoveu a Primeira Reunião Científica Mundial sobre Conservação e Utilização dos Recursos Naturais.

Não obstante, em face dos benefícios do modelo industrial fordista fossilista - identificado com desenvolvimento -, da disputa político-ideológica da Guerra Fria e das necessidades do capital, poucos atentaram para os limites do planeta diante das crescentes produção e produtividade exigidas pela acumulação de riqueza abstrata. Assentada em capitais privados ou sob a direção do Estado, a definição do padrão acumulativo teve como pressuposto a crença segundo a qual a ciência e a técnica sanariam os problemas que surgissem, apesar da crítica ao capitalismo, ou ao industrialismo, que foi ganhando corpo nos anos 1960, desdobrando-se na ecologia política e em tentativas de organização de pequenas comunidades resistentes a padrões consumistas.

As conquistas econômicas, sociais e sanitárias, restritas a certos países ou grupos sociais, melhoraram as condições ambientais e eram debitadas ao desenvolvimento; então, os problemas seriam apontados como heranças do passado. Nesta realidade, os países não industrializados apenas caminhariam um pouco atrás 
na estrada de mão única rumo à abastança. Aos pobres em geral, a teoria do desenvolvimento acenava com um futuro promissor.

Em meados dos anos 1970, quando o desejo de "ser desenvolvido" era dominante, findou o crescimento acelerado e as consequências ambientais negativas do desenvolvimento ganharam visibilidade. Remontam a essa década textos como Limites do crescimento e o trabalho de Georgescu-Roegen, incorporando as leis da termodinâmica à economia. A Conferência da ONU sobre o Ambiente Humano (Estocolmo, 1972), a progressiva absorção da discussão ambiental pelos organismos multilaterais e a multiplicação das ONGs ambientalistas também foram marcantes.

Após a divulgação do relatório Nosso Futuro Comum (1987), da Comissão Brundtland, o conceito de "desenvolvimento sustentável" popularizou-se e impulsionou a presença do Estado no debate. Embora não muito clara, a ideia de conciliação do desenvolvimento com a justiça social e a conservação da natureza seria repetida à exaustão. Na Conferência das Nações Unidas sobre Meio Ambiente e Desenvolvimento (CNUMAD), no Rio de Janeiro (RIO-92) o termo "desenvolvimento sustentável" foi incorporado ao discurso político e às agendas de governos e de organismos multilaterais.

Ao se expandir, o debate ambiental tornou-se mais complexO. Até a RIO-92, a orientação do Programa da ONU para o Meio Ambiente (PNUMA) indicava que a política ambiental internacional da família ONU compreenderia mecanismos para transferir recursos financeiros e tecnológicos dos países ditos desenvolvidos para os não desenvolvidos (NOBRE, 2002). Essa postura gerou contradições entre o PNUMA e o Grupo Banco Mundial, que até 1987 dispensara pouca atenção ao tema. ${ }^{1}$

1 O Grupo Banco Mundial - tal como o Fundo Monetário Internacional, embora pertença ao sistema da ONU, funciona com ampla independência. Objetivamente isso significa a desobrigação de cumprir a Carta das Nações Unidas, de colaborar formalmente com as demais organizações do sistema e de se pautar pela Declaração Universal dos Direitos Humanos. Significa também liberdade para definir as informações a serem repassadas para o Conselho Econômico e Social da ONU (PEREIRA, 2009). 
Porém, o fim da Guerra Fria e o avanço da globalização permitiram aos países doadores concentrarem recursos nas instituições multilaterais cujo voto é proporcional às contribuições e em programas bilaterais. Chegada a hora de formular propostas, a Conferência do Rio pendeu para a perspectiva gestada pelo Banco Mundial desde 1991, com o Global Environment Facility (GEF), cujo objetivo seria financiar ações ambientais com vistas ao desenvolvimento sustentável e ecologicamente racional.

Da criação do GEF participaram também o PNUMA e o Programa das Nações Unidas para o Desenvolvimento (PNUD). Estas duas presenças configuraram a estratégia de legitimação do projeto do Banco. Essa conclusão de Nobre, Jahn e Amazonas (2002, p. 289) deriva, dentre outros sinais, da constatação de que o PNUD embora "conselheiro técnico para a formulação de diretrizes e para a elaboração de projetos não teve qualquer participação na determinação das quatro áreas principais de atuação do programa". Além disso, o primeiro grupo de projetos financiados foi selecionado pelo Banco Mundial e apenas ratificado pelos estados-membro do GEF antes mesmo que o PNUMA elaborasse as diretrizes para a seleção dos projetos. ${ }^{2}$

Assim, a maior financiadora de projetos ambientais no mundo firmou parcerias com entidades internacionais, organizações não governamentais e com o setor privado pretendendo ser "independente" do Banco Mundial. Entretanto, cabe a essa instituição financeira a administração do seu Fundo Fiduciário.

A ascendência internacional do GEF repercutiu na formulação dos projetos ambientais; seus padrões e critérios foram adotados mesmo por projetos que não contam com o seu financiamento. Então, o Banco Mundial passou a deter hegemonia na fixação de parâmetros de financiamento, auditoria e controle de projetos em escala planetária. Tal hegemonia significou a prevalência da teoria

\footnotetext{
2 Hoje, o GEF congrega ainda a Organização das Nações Unidas para a Alimentação e a Agricultura, a Organização das Nações Unidas para o Desenvolvimento Industrial, o Banco Africano de Desenvolvimento, o Banco Asiático de Desenvolvimento, o Banco Europeu de Reconstrução e Desenvolvimento, o Banco Interamericano de Desenvolvimento e o Fundo Internacional para o Desenvolvimento Agrícola.
} 
econômica ambiental de extração neoclássica na determinação do "desenvolvimento sustentável" (NOBRE, 2002, p. 68).

Então, o "ambientalismo" foi assimilado por governos, acadêmicos e empresários. Multiplicaram-se as parcerias com o setor privado e as ONGs - algumas de visibilidade e alcance internacionais. Como ressaltado, a

construção de categorias abstratas, como as de humanidade, gerações futuras, qualidade de vida e outras [...] que dificultam a análise em termos de diferenças entre grupos sociais e entre nações, protegendo a proposta do Desenvolvimento Sustentável do enfrentamento de eventuais contradições no campo das relações sociais, disseminou-se (FERNANDES, 2003, p. 131, destaque da autora).

O adjetivo "sustentável" tornou-se presença obrigatória nos discursos políticos, acadêmicos e em programas governamentais.

No Brasil, a hegemonia da abordagem veiculada pelos organismos multilaterais pode ser constatada na literatura acadêmica. $\mathrm{Na}$ matriz do desenvolvimento sustentável inúmeros cursos técnicos, universitários, programas de pós-graduação e núcleos de pesquisa foram criados.

\section{A PERCEPÇÃO DA “CRISE AMBIENTAL”}

A percepção hegemônica é caracterizada como problemas decorrentes, em última instância, dos limites físicos do planeta ante os ilimitados desejos de uma população em crescimento. Não obstante, a tecnologia, a gestão e o aperfeiçoamento da organização social segundo princípios mercantis seriam capazes de construir uma sociedade fundada na solidariedade intra e intergerações, e de garantir o crescimento econômico, a justiça social e a conservação ambiental.

Partindo dessa concepção, predominam na literatura noções de que os processos físico-químicos seriam pontualmente responsáveis por "danos" específicos e soluções técnicas e/ou gerenciais. Trata-se de um ambientalismo de resultados. Neste prisma, a série Global Environment Outlook (GEO), publicada pelo PNUMA, merece atenção como uma das mais importantes do pensamento ambiental. Como exposto, o GEO-4, sugestivamente denominado Meio Ambiente para o Desenvolvimento, principia com 
a enumeração de ameaças geofísicas à vida humana e à ordem social:

Imagine um mundo no qual as mudanças ecológicas ameaçam a saúde, a segurança física, as necessidades materiais e a coesão social. Um mundo sujeito a tempestades mais e mais intensas e frequentes, caracterizado pela elevação cada vez mais inquietante do nível dos mares. Alguns são vítimas de inundações e outros de secas extremas. A extinção de espécies ocorre em proporções jamais observadas. A água potável é cada vez menos acessível, entravando as atividades econômicas. A degradação dos solos coloca em risco a vida de milhões de pessoas [...] (PNUMA, 2007a, p. 6).

Depois de apresentar as mudanças ocorridas desde a divulgação do texto Nosso Futuro Comum (1987), o GEO-4 discorre sobre a evolução dos aspectos institucionais e conceituais na busca do desenvolvimento sustentável. O leitor é instado a imaginar um mundo onde "o bem-estar humano é garantido a todos": ar puro e água potável acessível propiciariam melhores condições de saúde; o aquecimento global cessaria graças "a reduções de nosso consumo de energia e a investimentos em tecnologias limpas"; as "comunidades vulneráveis receberiam ajuda" e a integridade dos ecossistemas asseguraria a reprodução das espécies. Apelando para uma humanidade abstrata, conclui: a "transformação destas imagens em realidade está ao nosso alcance e cabe a nossa geração a responsabilidade de começar" (PNUMA, 2007a, p. 43).

Contudo, o GEO-4 homogeneíza os diferentes e esconde as contradições relativas à apropriação e uso da natureza. Para a sustentabilidade, caberia encontrar respostas para problemas arbitrariamente secionados em quatro esferas: internacional, regional, nacional e local. Em resumo, eis as respostas indicadas:

a) regulação e controle administrativo (normas, proibições, permissões, cotas, reparações jurídicas, etc.);

b) ações governamentais diretas (criação de infraestruturas ecológicas, zonas ou parques ecoindustriais, áreas desprotegidas, parques abertos à visitação, reabilitação de ecossistemas degradados); 
c) engajamento dos setores públicos e privados (participação, descentralização, educação, informação, certificação de produtos e parcerias);

d) utilização de mecanismos de mercado (ecotaxas, subvenções pontuais, eliminação de subsídios considerados perversos);

e) criação de novos mercados (instituição de direitos de propriedade, de permissões e direitos negociáveis, de programas de compensação ambiental, de fundos de investimentos ecológicos e aquisição de "produtos" verdes acompanhados de medidas de incentivo a estas inversões; pagamento por serviços ambientais).

Conforme sugere o relatório, a concretização destas ações estaria sendo viabilizada ao realçar as diferenças entre a atual conjuntura política mundial e regional e aquela em que foi elaborado o Relatório Brundtland. Dentre as mudanças que permitiriam responder à crise e alcançar o sonhado desenvolvimento estariam: maior integração da economia mundial via fluxos comerciais e financeiros; avanço tecnológico; integração do conhecimento mediante transferência de informações, de cultura e de tecnologias; mundialização das governanças; aumento da influência dos sujeitos não governamentais e empresas internacionais em um contexto tradicionalmente dominado por Estados nacionais.

Segundo o PNUMA (2007a), a institucionalização da questão ambiental seria uma condição para responder à crise. Os anos seguintes ao fim da Guerra, diz ainda o GEO-4, "renovaram o otimismo nas governanças multilaterais e mundiais" e nos anos 1990 foram estabelecidos fóruns mundiais sobre temas tão diferentes como: crianças, desenvolvimento sustentável, direitos humanos, demografia, desenvolvimento social, etc. De tais encontros resultaram

[...] declarações normativas e ambiciosos planos de ação, ilustrativos de uma nova unidade no modo pelo qual os governos e a comunidade internacional compreendem os complexos problemas mundiais e frente a eles formulam suas respostas (PNUMA, 2007a, p. 29). 
O relatório Meio Ambiente para o Desenvolvimento atribui ainda importância à formatação institucional da política ambiental: as reformas no sistema ONU, a criação da Corte Penal Internacional, o setor privado e a Organização Mundial do Comércio (OMC). Enfim, reforçou a competência da governança mundial numa conjuntura de absoluta hegemonia norte-americana.

\section{NOVIDADES COM SABOR ANTIGO}

Como evidenciado, as respostas à crise expostas no GEO-4 como regulação, controle administrativo e ações governamentais diretas há muito tempo são conhecidas. Ainda que apresentem novos formatos e significados, a instituição de leis de proteção ambiental e regras para impedir ou controlar a poluição das águas, resguardar a caça, o pescado, conservar espécies vegetais e a instituição de multas e punições para os infratores das leis antecedem o capitalismo.

A criação de espaços supostamente isolados do mundo natural é comum a diferentes sociedades. Grupos cuja sobrevivência dependia de recursos florestais sacralizavam as matas e as reservavam para rituais de iniciação de jovens no conhecimento das plantas curativas. A racionalidade não intencional subjacente às crenças, costumes, saberes e técnicas resultava em uma apropriação (simbólica e material) ${ }^{3}$ da natureza necessária à reprodução social (GODELIER, 1971, v. II; DIEGUES, 2001).

No velho mundo lusitano, as Ordenações do Reino, ${ }^{4}$ consolidação da ordem jurídica portuguesa, complementadas por Cartas Régias, Resoluções, Ordenações Avulsas e Alvarás denotavam conhecimento da natureza e o intento de normatizar e controlar o acesso e o uso dos seus recursos. Havia regras para o corte das árvores em terras comuns, para a preservação de certas madeiras,

3 A apropriação material e simbólica não implica dualismo, já que toda apropriação material é também simbólica. Lembra Porto-Gonçalves (2002): a sociedade só se apropria daquilo que guarda algum significado.

4 Ordenações Afonsinas (1446-1514); Manuelinas (1514-1603). As Ordenações Filipinas remontam ao domínio espanhol e começaram sua vigência em 1603. No caso brasileiro, elas foram válidas até a promulgação do Código Civil, em 1916 (OLIVEIRA, 2002). 
proteção das margens do Tejo, regulamentação da caça e da pesca, proteção de aves que se tornavam raras, abelhas e peixes nas Ordenações Manuelinas e Filipinas. ${ }^{5}$

Na modernidade, o estabelecimento de áreas para preservar espécies para a alimentação ou o deleite dos grupos abastados remonta aos Coutos Reais. Porém, as raízes mais próximas das atuais reservas estão na Inglaterra do século XVIII. Conforme Thomas (1988), com o avanço da indústria cresceram a poluição e a insalubridade das cidades, as matas foram substituídas por pastagens e inúmeras espécies animais e vegetais desapareceram. Esse quadro deu origem a um movimento de romantização da natureza sem precedentes no chamado Ocidente e às primeiras reservas particulares.

O romantismo surgiu e se desenvolveu exaltando o amor pela terra natal, imprescindível na construção das sociedades que viriam a ser conhecidas como "nacionais": o orgulho de integrar uma comunidade compreendia a valorização da beleza e da riqueza singulares encerradas no território habitado. Há versões em muitos idiomas de versos do tipo "minha terra tem palmeiras onde cantam os sabiás / as aves que aqui gorjeiam não gorjeiam como lá". O sentimento de apego à terra natal, mediante alta valorização da sua beleza e da sua generosidade para com os habitantes, foi maciçamente cultivado ao longo do século XIX pelo ensino primário, pela ficção literária, pelas artes plásticas e pela música. Com suas pretensões cosmopolitas e universalistas, a arte moderna não negaria a tendência de valorização da riqueza e da beleza da terra natal, aspectos fundamentais da construção do sentimento nacional.

O hobby de cultivar flores, a jardinagem, o vegetarianismo e as primeiras associações de proteção à natureza remontam a essa época. Frutos da destruição provocada pelo capital e por ele financiadas nasceram na Inglaterra as primeiras reservas particulares com fins contemplativos.

5 Informações obtidas em vários "Livros" e "Títulos" das duas últimas Ordenações do Reino disponíveis online. 
[...] os gostos educados dos estetas [foram] pagos pelos mesmos processos que eles afetavam deplorar. A família Hoare, que tornou Stourhead tão requintada, era de banqueiros londrinos que [devem] ter auxiliado a financiar muito da expansão urbana. Os Dudleys podiam se permitir a beleza de Himley, com suas árvores, parques e lagos, porque suas fundições acabaram com a paisagem de Staffordshire mais ao leste. O esteta Richard Knight era neto de um fabricante de ferro de Shropshire (THOMAS, 1988, p. 340).

No século XIX, após a fundação do primeiro parque nacional destinado a proteger áreas de grande beleza para usufruto de visitantes - Yellowstone (1872) - outras 37 áreas protegidas foram criadas pelo mundo. No século XX, sob pressão do moderno ambientalismo, tais espaços se multiplicaram. Entre 1970 e 1990 foram instituídas 2.098 áreas protegidas, predominantemente na América Latina e na África (DIEGUES, 2001).

Hoje, com diferentes graus de abertura para a sociedade, alguns destes espaços prestam-se apenas à pesquisa científica; outros admitem a permanência dos antigos moradores e a manutenção das suas atividades de subsistência. Há aqueles que permitem, limitadamente, novas construções e servem, essencialmente, ao prazer estético de grupos de alta renda. A privatização de ilhas e praias ao longo do litoral brasileiro, visível nas ricas residências de verão e nos resorts, assim como o recente turismo em Fernando de Noronha, são alguns exemplos.

Como tais espaços se originam da lógica capitalista e atualmente já nascem "[...] impregnados [...] do pensamento racional representado por conceitos como ecossistema, diversidade biológica etc." Diegues (2001, p. 13) qualifica esse pretenso isolamento como um dos mitos modernos.

Altvater (1995) lembra que ao salientar as diferenças entre os valores da sociedade industrial e um mundo ideal, as reservas expõem dilemas e contradições das sociedades atuais. Tal como suas antecessoras inglesas, reafirmam o modo de vida ao qual aparentemente se opõem transmitindo a mensagem de que a destruição provocada pela sociedade urbano-industrial é inevitável e necessária, mas pode ser compensada. 
Ademais, estas áreas propiciam lucro, reforçam diferenças sociais, segregam espacialmente e possibilitam pesquisas e reservas de recursos cujos resultados são apropriados pelo capital. O fato de muitos destes espaços serem contestados por aqueles que neles viviam, ou vivem, longe de invalidar sua integração ao processo de acumulação, reflete o movimento contraditório do capital e a concorrência entre seus diversos ramos (SILVESTRE, 2003).

Igualmente inseridas na lógica capitalista são a recuperação de áreas degradadas, o descarte de tecnologias e processos de produção antigos e sua substituição por meios modernos que consomem menos matéria-prima, o gerenciamento e o controle dos recursos que tendem à escassez pelo saber científico. A lógica mercantil aí embutida é reconhecida no GEO-4:

Está cada vez mais comprovado que os investimentos na gestão ambiental conduzem à elevação da renda das populações rurais pobres. Esse tipo de investimento pode, igualmente, representar rendas para as indústrias dos países desenvolvidos que produzem equipamentos para reparos ambientais. Na Dinamarca, por exemplo, a indústria ambiental constitui a segunda maior fonte de exportação (PNUMA, 2007b, p. 7).

Segundo este relatório "[...], a variedade e o alcance das opções de respostas com que contam os formuladores das políticas [ambientais] evoluiu progressivamente no transcurso dos últimos 20 anos" (PNUMA, 2007a, p. 29). As ações apontadas como inovadoras e priorizadas têm cunho financeiro e compõem, em especial, os últimos grupos de respostas sugeridas: incentivar investimentos privados por meio da descentralização e de parcerias em áreas como educação, informação, administração e gerenciamento de setores "problemas" entre os quais o abastecimento de água potável; ampliar a propriedade privada; criar permissões comercializáveis sobre bens e serviços ambientais até então bens livres; ${ }^{6}$ estimular a certificação de produtos e a formação de fundos de

6 Conforme o pensamento econômico neoclássico, bens livres são aqueles encontrados livremente na natureza e que, por serem abundantes, não fazem parte do sistema de propriedade privada. Para a racionalidade mercantil, apenas estes bens/recursos não devem ter preço. 
investimentos ecológicos e o pagamento por serviços ambientais a preços que revelem sua escassez.

O referido texto expõe os instrumentos econômicos e extra-econômicos de combate à crise, realçando a participação coletiva, educação, justiça e ética. Neste intento, a prioridade conferida aos instrumentos econômicos visa corrigir as "falhas de mercado". Consoante admite, em outras palavras, fora do mercado não há racionalidade. Ainda como lembra o GEO-4, a diretiva mercantil está ancorada na Declaração do Rio, cujo princípio 16 estabelece que:

[As] autoridades nacionais devem procurar promover a internacionalização dos custos ambientais e o uso de instrumentos econômicos, tendo em vista a abordagem segundo a qual o poluidor deve, em princípio, arcar com o custo da poluição, com a devida atenção ao interesse público e sem provocar distorções no comércio e nos investimentos internacionais.

Subjacente a esse princípio está a percepção dos problemas ambientais como efeitos externos do processo de produção ou resultados não previstos ou indesejáveis que recaem sobre terceiros, como custos capitalistas, os quais, por se encontrarem fora do sistema de preços, são assumidos pela sociedade. Ao se corrigir essa falha, ou seja, internalizando as externalidades, os problemas tenderão a diminuir ou desaparecer.

\section{A VALORAÇÃO DA NATUREZA}

De acordo com o pensamento econômico neoclássico, paradigma da visão hegemônica da questão ambiental, várias são as origens das falhas do mercado: fricções que reduzem a mobilidade dos fatores de produção (recursos naturais, capital e trabalho), conhecimento insuficiente do mercado por parte dos agentes econômicos, inadequação das instituições (interferência do Estado na alocação dos recursos) e a existência de bens/serviços escassos na condição de bens livres ou subsidiados.

Nesse raciocínio, o uso gratuito do ar ou da água seria ambientalmente nefasto por mascarar o verdadeiro custo da produção, impedindo a sinalização dos preços pelos mercados. Fora do sistema de preços, estes custos seriam externalizados na forma de danos ambientais. Como toda a sociedade sofreria tais danos ou 
arcaria com os custos para repará-los, configura-se a transformação de custos privados em custos sociais. Assim, a internalização das externalidades imputaria estes custos aos que os geraram.

Para os defensores da internalização, o artigo de Garret Hardin datado de 1968, "The tragedy of commons", é seminal. Como Bentham e Adam Smith, filósofos do individualismo, o biólogo considera que os homens agem movidos por interesses individuais - nesse caso, a busca da sobrevivência ditada pela seleção natural. Porém, ao entender que o todo não é igual ao somatório das partes, sua conclusão acerca dos resultados do individualismo é oposta à preconizada por ambos. Na sua percepção, a busca por vantagens individuais, com o passar do tempo, será catastrófica para a coletividade e os bens comuns.

Hardin (1968) supõe a utilização dos pastos comuns por camponeses possuidores de rebanhos individuais; como observa, espera-se que cada camponês se pergunte, com vistas a elevar ganhos pessoais: qual a utilidade de acrescentar um animal ao meu rebanho? O componente positivo desse acréscimo é o lucro que receberá sozinho pela venda do animal; é quase igual a +1 . O negativo é o sobrepastoreio, que dividido com todos os pastores representa apenas uma fração de - 1. Uma vez que os ganhos superam as perdas, a opção racional seria adicionar mais animais ao rebanho. Se todos fossem racionais, o grupo chegaria à mesma conclusão. Com o tempo e o crescimento da população, as pastagens se tornariam imprestáveis e a "tragédia" se instalaria.

São semelhantes as razões que levam ao aumento da poluição. O homem percebe racionalmente que o custo de tratar os resíduos antes de descartá-los é superior à sua cota-parte do custo social por não fazê-lo. Se todos são racionais, cada um pensará e agirá de forma semelhante. Desse modo,

"[...] estaremos presos em um sistema de 'poluir o próprio ninho', enquanto nos comportarmos como independente, racional, livre-empresa", afirma, antes de concluir que a "tragédia dos comuns" possa ser evitada pela propriedade privada ou por um sistema semelhante (HARDIN, 1968, p. 4). 
Essa é a lógica subjacente à apropriação da natureza na sociedade mercantil desenvolvida. Os capitalistas guiam-se pelo cálculo monetário e optam, ou não, pela produção de uma unidade adicional de certa mercadoria comparando os custos adicionais para produzi-la e a receita obtida com sua venda. Como a competição preside o mercado, cada capitalista procurará os mais diferentes meios para diminuir seus custos, dentre os quais, o máximo usufruto da propriedade comum. Embora cada um deles necessite destes bens, do ponto de vista individual, o zelo não é racional caso implique incômodos ou aumento dos custos de produção, até porque - é de se supor - esse raciocínio guiará todos os demais, ou seja, a concorrência.

Na hipótese de uso gratuito das águas de um rio como matéria-prima, manda a racionalidade capitalista não aumentar custos investindo em novas tecnologias com o fim precípuo de poupar água. Também não será por amor ao ambiente que os rejeitos da produção serão tratados antes de lançados aos espaços comuns. Num futuro mais ou menos distante, as consequências dessa postura afetarão tão negativamente a sociedade que a cota-parte das perdas individuais superará os ganhos. É nesse sentido que Altvater (1995) fala em transformação da racionalidade individualista em irracionalidade social e, em seguida, em irracionalidade microeconômica.

Para que a irracionalidade social e microeconômica não se instale, alegam os defensores da lógica mercantil, o sistema de preços deve refletir os custos reais das mercadorias. ${ }^{7}$ Essa é uma condição para que os sinais enviados pelo mercado induzam os agentes econômicos a decisões adequadas, ou seja, para que a racionalidade que preside as escolhas individuais maximize $\mathrm{O}$ bem-estar social.

A subestimação dos custos do uso gratuito ou subsidiado dos bens comuns acarreta distorções nos preços e induz vendedores e compradores a decisões que, racionais do ponto de vista individual, são prejudiciais à coletividade. Se os capitalistas pagam

7 Esta é a visão neoclássica e keynesiana de "custo real". Para Marx, esse é o custo aparente ou custo em trabalho pago. O custo real inclui trabalho pago (capital constante e capital variável) e não pago (mais-valia). 
pela matéria-prima utilizada preços reveladores da sua escassez e se os custos a eles imputados pelos danos ambientais que provocam forem superiores à receita obtida com a venda da mercadoria causadora do dano, a racionalidade individual lhes indicará a necessidade de tecnologias mais eficientes, de evitar desperdícios, de tratar os resíduos, etc. Assim, o ambiente será poupado.

Essa é uma "[...] leitura mercantil dos fenômenos sociais e reduz os processos que vicejam na interface mercado/não mercado a meros problemas de eficiência alocativa de recursos" que vê as relações não mercantis como desprovidas de razão, aponta Acselrad (1995, p. 135). A mercantilização da natureza presente em tal perspectiva é evidente na justificativa exposta no GEO-4 para o uso dos instrumentos econômicos em resposta à crise ambiental.

Os recursos naturais podem ser considerados como um ativo financeiro de uma carteira geral integrada por outros ativos e fundos materiais, financeiros, humanos, sociais etc. A gestão dessa carteira de forma adequada e sustentável, de modo a permitir maximizar seus lucros ao longo do tempo, é um sólido investimento. Essa gestão é igualmente central para o desenvolvimento sustentável (PNUMA, 2007a, p. 30).

O modo mais eficiente para valorar monetariamente a natureza seria a concessão de direitos de propriedade privada sobre bens e serviços ambientais definidos, socialmente reconhecidos e garantidos pelo Estado. Nesse caso, os preços dos bens e serviços fornecidos pela natureza seriam formados no mercado pela livre negociação entre ofertantes e demandantes. Essa alternativa corresponde à ampliação do espaço mercantil e tem na reforma hídrica chilena, ocorrida em fins da década de 1980, um exemplo acabado. Neste âmbito, a instituição do mercado de carbono exemplifica a partilha negociada da atmosfera: reconhece direitos mercantis sobre o ar.

Como observa Hardin (1968, p. 4), ao concluir que uma solução adequada para a "tragédia dos comuns" seria a privatização

[...] o ar e as águas não podem ser facilmente cercados, por isso [...] deve ser evitada por meio de leis coercitivas ou de dispositivos que tornem mais barato para o poluidor tratar seus poluentes do que descarregá-los não tratados. 
Com efeito, as barreiras materiais e sociais para a transformação de elementos da natureza em mercadoria são substantivas. Para contorná-las, Pigou (1946) propôs a correção das imperfeições do mercado pela intervenção do Estado: subsídios seriam concedidos para estimular os efeitos externos positivos e impostos seriam cobrados para inibir as externalidades negativas. Essa alternativa corresponde ao quarto grupo de respostas à crise ambiental sugerida pelo GEO-4.

Para calcular estes incentivos é preciso quantificar a natureza e conferir valor aos bens ou serviços ambientais por meio de técnicas de simulação do mercado e/ou pesquisas de campo que determinem aquilo que os economistas chamam "disposição a pagar" por determinados bens/serviços ambientais. Tais valores podem ser impostos na forma de taxas como cobrado em Fernando de Noronha e no Parque Nacional da Serra da Capivara ou referenciar negociações entre usuários - com interveniência maior ou menor do Estado -, como começa a ocorrer com os recursos hídricos no Brasil. Também com base em estimativas desse tipo são estabelecidas multas, como aquelas que recaem sobre empresas que acidentalmente poluem um curso d'água. Tal como a privatização pura e simples da natureza, estas alternativas se inserem na lógica do capital e reforçam a fé no mercado como ótimo alocador de recurso.

As negociações entre empresas privadas e comunidades ou entidades que detenham direitos sobre recursos ambientais comuns retratam a subjetividade e a assimetria de poder que preside a quantificação e avaliação monetária da natureza. No Equador, um acordo entre os índios Huaorani e a transnacional Agip Oil permitiu a essa última estender um oleoduto, construir uma plataforma de petróleo e extrair o óleo na província de Pastaza. Cada uma das seis comunidades Huaorani recebeu como pagamento uma escola, um curso de orientação à saúde, um rádio, um painel para captação de energia solar, 50 quilos de arroz, o mesmo peso em açúcar, duas bolas de futebol, 200 dólares em medicamentos e outras miudezas (PORTO-GONÇALVES, 2006). Além da subjetividade, conforme a parceria revela, foram "negociados" acesso ao que seria responsabilidade do Estado: educação e saúde. 
O acordo celebrado entre o laboratório farmacêutico Merck e o Instituto Nacional de Biodiversidade (INBio) da Costa Rica ilustra o uso dos supostos espaços isolados pelo capital, a atuação de certas ONGs e a mercantilização da natureza, ou melhor, da vida, por meio de uma parceria público-privada. Utilizando o conhecimento e a força de trabalho barata das populações originárias, o Instituto comprometeu-se a coletar amostras de biodiversidade biológica - plantas, insetos e microrganismos - nas áreas de conservação mantidas às expensas do Estado e prepará-las para a multinacional. A parceria certamente interessou à ONG e à multinacional. Para os países que compartilham recursos genéticos com a Costa Rica, o acordo é motivo de preocupação e para a poderosa ONG americana WRI, um exemplo a ser seguido (MARTINEZ-ALIER, 1995). ${ }^{8}$

Foladori (2001) aponta quatro tipos de dificuldades para a internalização das externalidades pela via tecnocrática: as de fundo, as teóricas e técnicas, as éticas e as políticas. A primeira é simples: se os ritmos da biosfera não possuem relação com cálculos econômicos e existem independentemente deles, não cabe esperar que revertam a entropia. Que exercício matemático indicaria o momento ótimo para que uma espécie deixe de ser capturada? A extensão dessa dificuldade pode ser dimensionada tendo em conta que a extinção de uma espécie de ave leva ao desaparecimento de meia espécie de mamífero, duas de peixe, 35 de plantas e noventa de insetos (ALTVATER, 1995).

No segundo grupo, cumpriria decidir o que considerar como externalidade. Os acidentes no trânsito? Engarrafamentos no trânsito diminuem a vida útil dos veículos, aumentam o consumo de combustível, o tempo de deslocamento de pessoas e mercadorias e os acidentes; provocam estresses que afetam a saúde dos indivíduos, seu desempenho no trabalho, os gastos com saúde, etc. Estes efeitos seriam externalidades? Quem internalizaria estes

8 Acerca da atuação de ONGs ambientalistas na Amazônia (brasileira) e suas relações com o mundo dos grandes negócios é oportuna a leitura da tese de Camely (2009). 
custos? Como calculá-los? Quem receberia as indenizações? (FOLADORI, 2001).

Dificuldades teóricas e técnicas para a quantificação e valoração do ambiente são reconhecidas também por quem as defende. Conforme o GEO-4 "na ausência de instituições mercantis, isto é, frente a um déficit de direitos de propriedade individual torna-se problemático valorar os recursos naturais e avaliar as políticas [ambientais]". Diferentes percepções da natureza e deficiências nas técnicas de valoração disponíveis são outros problemas apontados pelo GEO-4, que reconhece nas avaliações tecnocráticas, tal como naquelas feitas pelo mercado, "lacunas em questões de equidade distributiva e intergeracional". Apesar disso, o relatório considera a quantificação e valoração da natureza "um instrumento precioso para examinar as complexas relações e as retroações entre ambiente, crescimento econômico e bem-estar humano" (PNUMA, 2007a, p. 30-32).

Contudo, a valoração ambiental pela via tecnocrática contraria a lógica e a ética neoclássicas. Segundo pressupõe a teoria, os preços resultam do encontro de vendedores e compradores livres para fazerem suas escolhas em um mercado real, diante de alternativas conhecidas. Escolhas hipotéticas entre situações inexistentes, derivadas da imaginação de técnicos e pesquisadores, fogem à pretendida objetividade e ferem o princípio da liberdade individual tão caro ao pensamento neoclássico. Ademais, na ausência da mão invisível, os preços de mercado perdem sua naturalidade, outro alicerce da economia neoclássica, sublinha Foladori (2001).

Ainda como exposto, a observância da racionalidade microeconômica gera problema ético também com as gerações atuais, afirmam Martinez-Alier (1995) e Foladori (2001), diante dos argumentos de Lawrence Summers para justificar a localização de atividades poluentes e perigosas nos países de população pobre. Em 1991, segundo argumentava Summers, ex-presidente do Tesouro dos Estados Unidos e da Universidade de Harvard, então no Banco Mundial, a alternativa maximizaria o uso dos recursos escassos porquanto as indenizações e multas decorrentes de danos contra pessoas são calculadas em razão da esperança de vida e da renda 
dos atingidos. ${ }^{9}$ De fato, essa seria a alternativa indicada pelo cálculo econômico, melhor dizendo, pelo capital. Assim, a própria teoria neoclássica mostra a oposição entre a racionalidade individualista que permeia sociedades cujo móvel é a acumulação da riqueza abstrata e o chamado desenvolvimento sustentável, em nome do qual as internalizações são propostas.

A última dificuldade apontada por Foladori estaria na interposição de barreiras políticas em diferentes escalas espaciais e instâncias de poder. Na formalização dos acordos acerca das emissões de $\mathrm{CO}_{2}$, por exemplo, seria prioridade diminuir as emissões ou ampliar as áreas de absorção? Como os maiores emissores não coincidem com os grandes absorvedores, os sacrifícios de uma ou outra decisão possuem pesos necessariamente diferentes para as partes.

Cabe ressaltar: a valoração econômica da natureza como mecanismo para poupar recursos ou minorar danos reforça o mercado independentemente dos caminhos e instrumentos escolhidos, das fragilidades ou sofisticação das técnicas utilizadas e das assimetrias nas relações de poder entre negociadores e tem levado à progressiva privatização dos bens. Sorrateiramente, entretanto, tal perspectiva alcançou governos, instituições multilaterais, universidades e grande número de ONGs.

\section{REFERÊNCIAS}

ACSELRAD, H. Externalidade ambiental e sociabilidade capitalista. In: CAVALCANTI, Clovis (Org.). Desenvolvimento e natureza: estudos para uma sociedade sustentável. São Paulo: Cortez; Recife: Fundação Joaquim Nabuco, 1995. p. 128-138.

ALTVATER, E. O preço da riqueza: pilhagem ambiental e a nova (des)ordem mundial. Tradução de Wolfgang Leo Maar. São Paulo: UNESP, 1995.

BENTHAM, J. Uma introdução aos princípios da moral e da legislação. Tradução de Luiz João Baraúna. Consultoria de José Américo Motta Pessanha. São Paulo: Nova Cultural, 1989. p. 1-58. (Coleção Os Pensadores).

9 Lant Pritchett assumiu a autoria do texto assinado por Summers que, por sua vez, declarou que tudo não passou de uma brincadeira. 
CONFERÊNCIA DAS NAÇÕES UNIDAS SOBRE DESENVOLVIMENTO E MEIO AMBIENTE. Declaração do Rio sobre Meio Ambiente e Desenvolvimento. Disponível em: <www.mma.gov.br/port/ sdi/ea/documentos/convs/decl_rio92.pdf>. Acesso em: 10 ago. 2009.

COMISSÃO MUNDIAL SOBRE MEIO AMBIENTE DESENVOLVIMENTO. Nosso futuro Comum. 2. ed. Rio de Janeiro: Fundação Getúlio Vargas, 1991.

DIEGUES, A. C. S. O mito moderno da natureza intocada. 3. ed. São Paulo: Hucitec, Núcleo de Apoio à Pesquisa sobre Populações Humanas e Áreas Úmidas Brasileiras, USP, 2001.

FERNANDES, M. Desenvolvimento sustentável: antinomias de um conceito. In: FERNANDES, Marcionila; GUERRA, Lemuel (Orgs.). Contra-discurso do desenvolvimento sustentável. Belém: Associação de Universidades Amazônicas, 2003. p. 131-169.

FOLADORI, G. Limites do desenvolvimento sustentável. Campinas: Editora da Unicamp, 2001.

HARDIN, G. The tragedy of the commons. 1968. Disponível em: $<$ http://www. garretthardinsociety.org/articles/art_tragedy_of_ the_commons.html >. Acesso em: $18 \mathrm{dez} .10$.

HOBSBAWM, E. A era dos extremos; o breve século XX - 1914 1991. Tradução de Marcos Santarrita e revisão técnica de Maria Célia Paoli. São Paulo: Companhia das Letras, 1995.

JAPÃO. Economia - Consulado Geral do Japão no Rio de Janeiro. Disponível em: <http://www.rio.br.emb-japan.go.jp/ caracteristicas/economia.htm>. Acesso em: 20 ago. 2013.

MARTINEZ-ALIER, J. De la economia ecológica al ecologismo popular. 3. ed. Montevideo, Barcelona: Nordan-Comunidad, Icaria, 1995.

MELLO, A. F. Marx e a globalização. São Paulo: Boitempo, 1999.

NOBRE, M. A Conferência do Rio: a definição das amarras institucionais e o novo estatuto do desenvolvimento sustentável. In: NOBRE, M. AMAZONAS, M. C. Desenvolvimento sustentável: a institucionalização de um conceito. Contribuição de Roland Jahn, Andreas Stöhr e Gilberto Tadeu Lima. Brasília: IBAMA, 2002. pt. 1, 
cap. 2, p. 49-69.

NOBRE, M. JAHN, R. AMAZONAS, M. C. O desenvolvimento sustentável institucionalizado: uma incursão pelo Global Environment Facility. In: NOBRE, Marcos; AMAZONAS, M. C. Desenvolvimento sustentável: a institucionalização de um conceito. Contribuição de Roland Jahn Andreas Stöhr e Gilberto Tadeu Lima. Brasília: IBAMA, 2002. pt. 3, cap. 1, p. 287-314.

OLIVEIRA, A. S. A codificação do Direito. Jus Navigandi, Teresina, ano 7, n. 60, nov. 2002. Disponível em: <http://jus2.uol.com.br/ doutrina/texto.asp?id=3549\&p=2>. Acesso em: 7 out. 2010.

PEREIRA, J. M. M. O Banco Mundial como ator político, intelectual e financeiro (1944-2008). 2009. $366 \mathrm{f}$. Tese (Doutorado em História) - Instituto de Ciências Humanas e Filosofia, Universidade Federal Fluminense, Niterói, 2009.

PIGOU, A. C. La economía del bienestar. Tradução para o espanhol de F. Sanches Ramos. Madri: Aguilar, 1946.

PORTO-GONÇALVES, C. W. A globalização da natureza e a natureza da globalização. Rio de Janeiro: Civilização Brasileira, 2006.

PROGRAMA DAS NAÇÕES UNIDAS PARA O MEIO AMBIENTE - PNUMA. L'avenir de l'environnement mondial (GEO-4). L'environnement au service du développement. Tradução para o francês de Phoenix Design Aid. Dinamarca: PNUMA/Phoenix Design Aid, 2007a. Disponível em: <http://www.unep.org/geo/ GEO4/report/GEO-4_Report_Full_FR.pdf>. Acesso em: 8 maio 2010.

L'avenir de l'environnement mondial (GEO4).

L'environnement au service au développement. Résumé pour les decideurs. Tradução para o francês de Phoenix Design Aid. Dinamarca: PNUMA/Phoenix Designer Aid, 2007b. Disponível em: <http://www.unep.org/geo/GEO4 /media/GEO4_SDM_French_ FR.pdf>. Acesso em: 8 maio 2010.

SILVESTRE, M. E. D. Água doce no Brasil - razões de uma nova política. 2003. 134 f. Dissertação (Mestrado em Desenvolvimento e Meio Ambiente) - Universidade Federal do Ceará, Fortaleza, 2003. 
THOMAS, K. O homem e o mundo natural: mudanças de atitudes frente às plantas e os animais, 1500-1800. Tradução de João Roberto Martins Filho, consultor da edição Janine Ribeiro e consultor dos termos zoológicos Márcio Martins. São Paulo: Companhia das Letras, 1988. 